\title{
The Development of Open University New Generation Learning Model Using Research and Development for Atomic Physics Course PEFI4421
}

\author{
Prayekti ${ }^{1, *}$ \\ ${ }^{1}$ Faculty of Teacher Training and Education, Open University of Indonesia, Indonesia \\ *Correspondence: Faculty of Teacher Training and Education, Open University of Indonesia, Indonesia. E-mail: \\ prayekti@ecampus.ut.ac.id
}

Received: July 21, 2017

Accepted: August 17, 2017 Online Published: September 22, 2017

doi:10.5430/wje.v7n5p1

URL: https://doi.org/10.5430/wje.v7n5p1

\begin{abstract}
This research was aimed at developing printed teaching materials of Atomic Physics PEFI4421 Course using Research and Development (R \& D) model; which consisted of three major set of activities. The first set consisted of seven stages, the second set consisted of one stage, and the third set consisted of seven stages. This research study was scheduled at the first year of the course development. This study concluded that (1) the teaching materials used for Atomic Physics Course PEFI4421 were necessary to be revised and updated since many of the materials were outdated, (2) the materials and concepts of Atomic Physics were hard to be learned by the students independently without face-to-face tutorials, (3) the exercises used in the handout were not clearly described in detail making them to be difficult to be completed, and (4) the physical presentation of the course materials needed improvement because they are lack of attractiveness for the students to use.
\end{abstract}

Keywords: Atomic Physics; $R \& D$; development; model

\section{Introduction}

Atomic Physics subject is one course to be completed by Bachelor degree's students of Physics Education, which is classified as a middle level course. This means that the course is the next course taken after Basic Physics Course before the students continue to advanced physics courses such as Core Physics, Statistical Physics, or Solid-State Physics. There are constraints experienced by the students regarding this course and of them is the uneven explanations and descriptions of the materials written by the previous Open University handbook writers. Therefore, in order to solve that issue there are revisions and improvements to be completed on the materials in essence that the revised versions may be better accepted by the students with various characteristics and circumstances in accordance with the present development of technological era. In particular, for the Physics Education Department of the university, Atomic Physics course is suitable to be served as the pilot project for Research and Development (R \& D) research study in promoting a new generation learning model of the Open University.

The opinions put forward by the Bachelor Degree's students of Physics Education, Faculty of Education-Open University Indonesia who have completed Atomic Physics Course PEFI4421 are diverse. They based their opinions on their personal experiences ranging from the use of the internet to study and achieve a good learning achievement and those who do not. During a telephone interview with a student from Central Maluku (UPBJJ-UT Ambon) on 14 February 2016, it was said that Atomic Physics Course that he took in Ambon, especially regarding with the final-term examination he had, was considered to be quite hard for him yet from the teaching materials provided were considered to be excellent in quality, regarding the fact that he managed to understand one exam question but could not finish writing his answer. This happened because he said that he could not complete any suggested summary of the materials due to the limited time he had which was filled with teaching sessions in his school. He later continued that he got $\mathrm{D}$ for the Atomic Physics Course and he had to retake it three times yet he still got D in each of his attempt. This then discouraged him to retake the course. Meanwhile, a different opinion was given by another student from UPBJJ-UT Purwokerto who explained that in order to successfully complete the course it is essential to have a thorough understanding and he did it through repetitively reading the available handbook and materials, and if he could not understand one point he would look for the answer or explanation from the internet. 
Still, if he could not find any satisfying answer, he would then ask his colleagues or student peers from UPBJJ-UT Purwokerto through online-discussions although it took a while for his friends to answer the questions even some did not respond at all. By the end of the course he got $\mathrm{C}$. In this practice, the student is considered to be internet-literate since he manages to use the internet as one learning source.

As stated in the Law of the Republic of Indonesia Number 20 Year 2003 on National Education System, Article 31 that (Paragraph 2) "The function of Distance Education is to provide services to groups of people who cannot enrol in person or in a regular meeting" and (Paragraph 3) that "Distance education is to be held in various forms, modes, and coverage which is supported by learning facilities and services as well as assessment that ensure the quality of the graduates in accordance with national education standards".

On the catalog of Indonesian Open University (2011: 23) it is written that "teaching materials play a fundamental role in transferring knowledge and the main teaching materials that the university have are in the printed instructional materials called Buku Materi Pokok (BMP) which are usually called modules. The teaching materials intended for independent learning are specifically designed to be easily studied independently by the students according to their ability level.

To further ensure the quality of the teaching materials, since 2008 there have been more than 100 teaching materials of the university that have been examined by prominent experts from various leading universities. The results show that, in 2008, in average the quality of each course material as well as a whole fell in the category of good. Besides, more than $80 \%$ of the experts who examined the materials stated that they would use the teaching materials as one reference of their own teaching (Budiwati, 2010). If the learning targets are achieved well then the quality of education can be ensured since one main issue which has been encountered by education until now is strongly related to the issue of quality and efficiency (Ibrahim, 1994: 14). One of the initial activities to improve learning learning is to design instructional materials that are in compliance with a model of development in attempt to facilitate learning (Degeng, 1989). Designing learning can then be used as the starting point of learning quality improvement efforts. Improvements of learning quality must be preceded by improving the quality of instructional design and the learning design system approach (Degeng, 1999: 2). An important factor in designing instructional materials is that the organisation of the content should be relied upon the characteristics of the content structure of the course in order that it can improve the learning achievement and retention rather than just following the structure of the textbook (Degeng, 1989). Reigeluth (1992: 22) also suggests that it would be better if the teaching materials be modified in accordance with the standard blueprint that answers particularly to the identified learning needs. In the same vein, Dimyati (1993: 2) confirms that learners who are strongly associated with the learning resources will internalise the knowledge and be expected to improve in cognitive, affective, and psychomotor aspects.

Instructional materials are positioned as sources of operational information for learning process organisation. The basic argument that underlies this is that instructional materials function as learning guidelines for the learners either within the context of independent learning or scheduled face-to-face class meetings equipped with learning methods, assessments, and outlines. According to Dick and Carey (1990), putting forward a system approach as the basis or underlying reason means putting the fundamental position for instructional materials for learning as described in the following points:

1. The focus of learning. The focus of learning is defined as what is known to the learner and what should be done; without a clear statement in the teaching materials, sequential plan and implementation steps, the focus of learning is likely to be unclear and ineffective.

2. The accuracy of links between learning components, especially the strategy and expected outcomes. Through the teaching materials the specific learning targets (knowledge/ability) will then be clearly explained which will in turn be executed within the previously prepared learning environment. These all should be clearly defined in the instructional materials.

3. The empirical process that is repeatable. The learning environment should be designed not only for one time but the practice should be able to be repeated as many times as possibly required.

According to Degeng (1989), the teaching materials must possess certain characteristics such as (1) the content should be analysed and classified into a certain category accordingly, (2) the category should be adequately supported in several written paragraphs in one text, (3) the importance of format presentation of visualisation in attempt to provide the attractiveness of the content, as well as (4) the category of title format that mentions the selected materials. Moreover, in order that the teaching materials can facilitate learning every material teaching material needs to be in compliance with the relevant components of the learners' needs. These components must 
provide motivation for, be easy to learn and understand by the learners. More importantly, they need to be highly relevant to the features of the intended course. Besides, the materials must also have certain characteristics that distinguish them from other books (Degeng, 1989). The kind of teaching materials that facilitate learning are those that have clear components which include (1) the general purpose of learning, (2) specific purpose of learning, (3) specific instructions to use the materials, (4) systematically arranged descriptions of the content of the materials, (5) images or illustrations that clarify the content of the lesson, (6) summary, (7) formative assessment and follow-ups for the next learning activities, (8) reading list, and (9) answer key.

Teaching materials that will be researched and developed are those which provide obstacles for learning and have a specifically low rate of learning achievement of the learners (under 50.00). With this regard, one teaching material that represents them is that of Atomic Physics course-book. There fore the research problem is then formulated as (1) How is the design of the learning strategies arranged for the teaching materials of the new generation of Open University Indonesia to solve the problems identified in learning Atomic Physics and (2) How is the preliminary form of the learning materials which are designed based on the learning strategies appropriate to address the issue of learning Atomic Physics.

\section{Literature Review}

\subsection{Distance Education and Use of Technology}

In today's global era, willingly or not, we have to keep ourselves familiar to the internet especially in respect to the information technology. This is due to the fact that technology has touched upon all the aspects of human life as a whole in everyday life. Thus, it is suggested that we all not be internet phobic in a way that we can get along and communicate well with other people around the world. Information Communication Technology (or ICT) has recently been growing rapidly and is a global phenomenon. Technology has become part of Indonesian culture ever since the domestic communication satellite system was developed. The development also reaches the education system. The importance of education for the nation has long been acknowledged by our founding fathers who state this in the 1945 Constitution Law that "every has the right to education". It does not seem to be excessive to state that, remembering the fact that education as one of the most fundamental aspects in human life, education be put as a priority. Even though in the macro viewpoint of human resource development should also cover social and economic aspects, it is posited that the main domain and key is education. For these reasons, it is then understandable that the Indonesian government puts Distance Education as one of many attempts to improve education in order to improve the quality of human resources of the nation.

With the aforementioned points, the author, in this respect, will discuss the efforts made by the government to improve the equity of education in Indonesia especially that of Distance Education. The focus of this study discusses the influence of ICT on Distance Education in Indonesia and in Indonesian Open University in particular which was founded in 1984 by the President of the Republic of Indonesia. A hands-on approach to introduce the chemical elements and the atomic structure to elementary/middle school students is described. The proposed classroom activity presents Bohr models of atoms using common and inexpensive materials, such as nested plastic balls, colored modeling clay, and small-sized pasta (or small plastic beads).

\subsection{Distance Education Teaching Materials and Distance Education Students}

Distance Education System, which is perceived as a innovative breakthrough in the 21st century, is one type of education system that has a broad range of coverage across space, time, and socio-economy. It opens access to education for anyone, anywhere, and anytime. With these characteristics, Distance Education System is often considered as a solution to education problems, especially with regards to equity and democratisation of education, as well as expansion of access to quality education to all levels of society across space and time. Through a variety of legal instruments that have been issued by the government such as the Decree of the Minister of Education No. 107/U/2001, National Education System Regulation No. 20/2003, Enactment of Government No. 17/2010 and No. 66/2010, Distance Education System has become an integral part of education in Indonesia, has become an option for the public to gain access to education, which includes teacher education and education personnel.

In its development, Distance Education System takes the advantages offered by media and learning technologies that bridge the need for education under nationwide circumstance. In particular, the rapid technological developments bring a model of education that is flexible and intelligent, and able to open the access to education by crossing the borders of space and time as well as socio-economy. Through this mode of education system, anyone can gain access to quality education without leaving their family, home, work and career opportunities. Besides the gained access, 
Distance Education System also offers an improvement of the equity of quality education for everyone. The characterised features of mass system of Distance Education in distributing standardised quality education using ICT, standardised learning outcomes, instructional materials, learning process, learning support, and assessment lend itself to the idea of an opportunity of obtaining quality education to people across space, time and socio-economy.

\subsection{Instructional Design for Distance Education System}

In regard to implementing Distant Education System, it is required to have a $\mathrm{n}$ adequately strong theory that will have a direct influence onto the practical aspects of Distant Education System. Furthermore, through implementing the theory, each and every decision can then be reached between the theory users in manifesting the theory such as in selecting methods, media, or funds and services that can be provided to the students to be arranged better and more thoroughly. This also helps removing negative effects that have previously been identified or those which unexpectedly occur in the future so that all the drawbacks can be minimised. The availability of adequately supporting theories will only make Distance Education System be more popular and the system itself will have a robust character to be offered to the public.

\subsection{Distance Education in Indonesia}

According to Suparman (in Asandhimitra, 2004: iii) Distance Education has been widely known after the first of it was founded in Great Britain with their Open University introducing a distance education approach. The success of this pioneer in distance education soon attracted the world's attention and encouraged them to organise one of their own in their country. The number of countries which organise this type of education system has gradually increased since then and the trend is not limited only to the world's developed countries but also to the developing countries, including Indonesia. In Indonesia, the Distance Education System has quite a long history. In regard to its initial implementation, Distance Education is set forth in a legal document of the Enactment of the Republic of Indonesia No. 20/2003 under National Education System heading. The formulation for the Distance Education is stated at Point Ten of Article 31, which states that (1) the Distance Education is to be held at all lanes, levels, and types of education; (2) the Distance Education is aimed at providing educational services to groups of people who cannot pursue their education on face-to-face and regular basis; (3) the Distance Education is organised in various forms, modes, and coverage supported by learning facilities and services as well as assessment system which ensures the quality of the graduates to be in compliance with the national standards of education; (4) the regulations set for the Distance Education System as stated in point (1), (2) and (3) are then explained in the government enactments (Sanaky, 2011: 209).

The Open University, in particular, is a breakthrough initiated by the government, in this case the Ministry of Education and Culture. It is a result of thorough research and examinations drawn upon previous experiences had by the nation in organising Distance Education System and other countries such as India (Indira Gandhi National Open University), Thailand (Sukothai Thammatirat Open University), Korea (Korean Open University), United Kingdom (The Open University UK). The Open University in Indonesia was establish in September 1984 through a Decree of the President of the Republic of Indonesia, which aims to provide access to higher education for high school graduates and academic improvement for professional qualification, especially for teachers (Prawiradilaga, 2004: 265-267).

Advances that happen in the world of ICT create new opportunities and challenges in education. The emerging opportunities include the widening access to multimedia content that is richer and more developed. This promotes the idea to develop a new learning method that is no longer limited by time and space called online tutorial. The arranged online tutorial that is held by the Open University in Indonesia is set in eight meetings, with each meeting containing initiation and discussion on topics. In a recent occasion, the number of students who were registered to enrol in the online tutorials was 31 , at the sixth meeting for online tutorial there were only 20 students who took part, and none of them managed to send the first and second task assigned by the lecturer with a variety of reasons. This incident indicates a fact that the interactions between the lecturer and students were not thoroughly paid attention to. This might be because there was a malfunction in the online system or else that was not identified by the lecturer of the online tutorial in the Open University Centre.

Regarding independent learning, all the students are required to have their own initiative to study the materials, do the assigned tasks, strengthen the learning skills, and apply their learning experiences to the work. Independent learning does not necessarily mean learning only by yourself but can also be manifested in a group learning such as that initiated during the tutorial activities period. Independent learning with the main principle of being independent is expected to be embodied in any learning activities completed by the students either by themselves or in groups of learning. The lecturers merely function as the facilitator to provide assistance or support to the students in a way that 
the service provided is as minimum as possible adjusted with the learning environment. In an independent-learning system accompanied with the provided support of face-to-face tutorials, the well-preparedness of the students are fundamental; only with adequate preparation can the tutorial activities be well-conducted as expected. It is in this certain path that the students may then participate actively and optimally benefit from the tutorials to master the initially prescribed course competencies. In line with this statement, Pribadi et al. (2005) states that "is the students experience any difficulties in their study, they can then ask for help from the lecturer through face-to-face during the tutorials or outside of the tutorial time" and that instructional materials are one essential element in distance education as explained by them that "the teaching materials hold a central role in transferring knowledge in distant education and the quality has to be continuously improved, either in terms of the content or physical presentation".

\subsection{Research and Development $(R \& D)$}

$\mathrm{R} \& \mathrm{D}$ study is a process used to develop and validate an education product or one type of research method used to produce a certain product and test the effectiveness of that product. Borg and Gall (1989) put it this way: "education research and development is a process used to develop and validate an education product". Results of R \& D is not limited to a development of an existing product, but also an identification of new knowledge or an alternative answer of a practical issue. According to Sugiyono (2012), R \& D is one type of research method that used to produce a particular product and test the effectiveness of it. In order to be able to produce a certain product, a research based need analysis is required (using survey or qualitative data collection method), while to test the effectiveness of the product in order that it be beneficial for a wider public it is necessary to have an experimental research method. Furthermore, Borg and Gall (1989) state that basic research method is widely used to produce a product that is hypothetical as the need analysis data collection. Then, to test the product that is still hypothetical it is important to conduct experiments which is also called as action-research. After the product is tested, it then needs to be applied. The process of testing the product using experiments is called applied research. In regard to this, since R \& D aims to identify, develop, and validate a specific product, R \& D is considered to be longitudinal in nature. In this case, the result is in the form of a curriculum that specifically answer the needs of a certain education level comprising the teaching methods, educational media, textbooks, modules, competence of the staff, evaluation system, competency test models, classroom management, staff management system, payroll system, and others (Sugiyono, 2009). The product can be in the form of software or hardware. Software products meant can be a program for data processing, classroom learning, educational model, instructional training, guidance, evaluation, and management. Meanwhile, hardware products meant can be books, modules, teaching aids, laboratory equipment, or else. $\mathrm{R} \& \mathrm{D}$ is different from common research in a way that common research is limited to providing suggestions for improvement, while $\mathrm{R}$ \& D produces readily used products. A hands-on approach to introduce the chemical elements and the atomic structure to elementary/middle school students is described. The proposed classroom activity presents Bohr models of atoms using common and inexpensive materials, such as nested plastic balls, colored modeling clay, and small-sized pasta (or small plastic beads).

\section{Research Methods}

\subsection{Research Approach and Development}

$\mathrm{R} \& \mathrm{D}$ is one research activity and the term development in business term offers a commercial value. One characteristic of R \& D is the it is a combination of pure scientific research and applied development in technology. R \& D plays an important role and is one indicator of the progress of a country. Sugiyono (2012:3) remarks that "research method can be defined as one scientific technique to obtain data to be used for certain purposes and functions". Research methodology consists of techniques to organise scientific research procedures and implementations in various disciplines at once". Drawn upon the above opinions, it can be concluded that a research method is a scientific procedure to obtain data needed to serve the intended research purposes.

$\mathrm{R} \& \mathrm{D}$ is used in this research study since it is in line with the research purpose of identifying and developing a new product, which is a teaching material, for the new generation of the Indonesian Open University specifically for Atomic Physics PEFI4421 course. As stated by Sugiyono (2012: 407) that "R \& D is a type of research method that can be used to create a certain product and test its effectiveness". So as said by Bord and Gall (in Sugiyono, 2012: 9) that $\mathrm{R} \& \mathrm{D}$ is a research method used for developing or validating products used in education and learning. In short, the selection of $\mathrm{R} \& \mathrm{D}$ supports the purpose of conducting this research study. 
Step 2

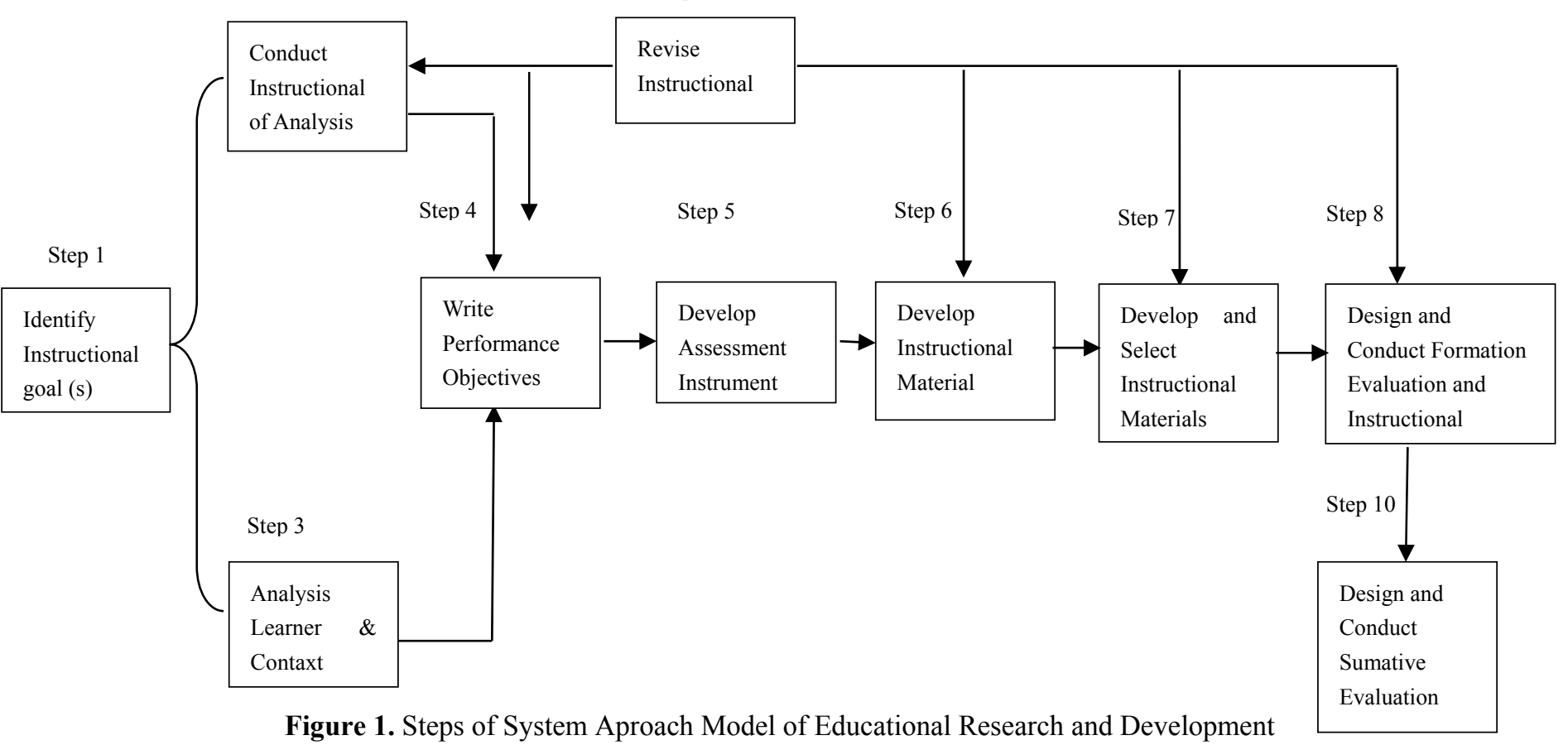

(Gall, Joyce \& Borg, 2007)

Source: Adapted from Figur 6 on pp. xxii-1 in: Dick, W., Carey, L., \& Carey, J. O (2005). The systematic design of instruction (6th ed.). New York: Allyn \& Bacon, Published by Allyn and Bacon, Boston, MA. Copyright 2005 by Pearson Education. Adapted with permission from the publisher.

\section{R \& D untuk Pengembangan Model Bahan Pembelajaran} Generasi Baru UT

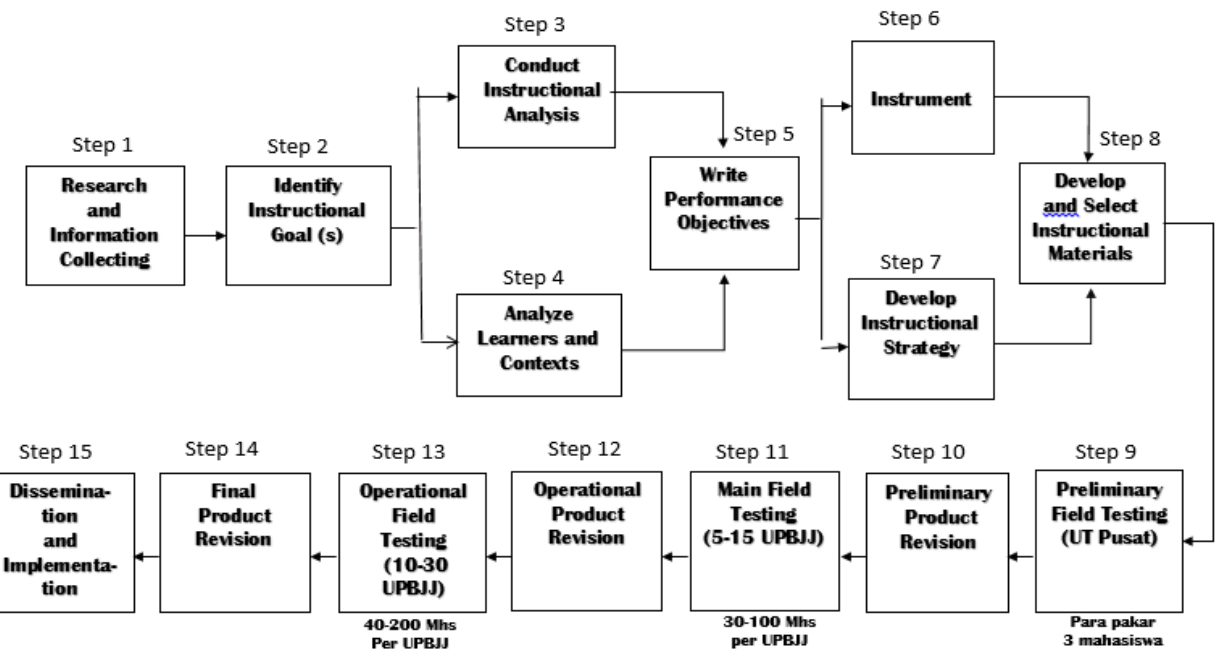

Figure 2. Developing R \& D For Model Learning Material New Generation Open University

\subsection{Stages of Conducting Research and Development}

R \& D Stages First year Activities

Step 1 Research and Information/Data Collection

Step 2 Instructional Goals identification 
Step 3 Instructional Analysis Completion

Step 4 Learners and Contexts Analysis

Step 5 Performance Objectives Writing

Step 6 Assessment Instrument Development

Step 7 Instructional Strategy Development

\section{Findings and Discussions}

\subsection{Research and Information/Data Collection}

The students' learning results of Atomic Physics have been very low for the last two years, the following table describes the average results of the students in the last four semesters

Table 1. The Average of the Students' Learning Outcomes in Atomic Physics PEFI 4421 Course

\begin{tabular}{llll}
\hline $\mathbf{2 0 1 4 . 1}$ & $\mathbf{2 0 1 4 . 2}$ & $\mathbf{2 0 1 5 . 1}$ & $\mathbf{2 0 1 5 . 2}$ \\
\hline 34,78 & 37,74 & 33,25 & 34,54 \\
\hline
\end{tabular}

Source: Pusjian UT 2016

Based on Table 1 above, it can be concluded that the average of the students' learning outcomes was below the minimum passing grade and was far from satisfying. This means that there are still awaiting tasks to accomplish in order to improve this condition. One of them is improving the quality of the teaching materials provided to the students by the university as well as the test items used to measure the students' learning outcomes holistically. One possible solution is then to have teaching materials that are easy to learn by the students independently that are suitable with the characteristics of the future students. According to the students, the level of difficulty of Atomic Physics course was "very hard", the difficult points of atomic physics mentioned were mostly at the explanations of the concept that were not detailed as well as the samples of question and the discussions that were still hard to follow. Moreover, almost all students said that they had no friends to consult or discuss this.

The students who joined online tutorials of Atomic Physics experienced difficulties in understanding the initial explanations that were not detailed, although they had set a certain time to learn and follow the provided online tutorials. The activation for each initiation for each student was between three and five times. Some students experienced some technical issues such as not being able to download an assigned task or find the results of their calculation were mismatched with the answer keys even using the same formulation. One suggestion given by some of the students was to provide samples of question and the answers that are detailed and easy to follow.

In one semester, according to a lecturer of the online tutorials, the total number of students who were supposed to be participating in the tutorials was 32 with only 12 students to pass the minimum passing grade. The passing score range was between 60 and 98: 9 students got 76, 2 students got 60 and 75, and 1 student got 98 .

A student from UPBJJ-UT Jember said that the module used in Atomic Physics was so thick and quite a burden, the formulas were also hard to memorise, the final exam questions were hard to answer and the time allocation to complete the exam was too short, the symbols used were too many and hard to memorise as well. He further suggested that for the students who failed the course (got D or E) to be encouraged by assigning them a task for that can change their score to pass. He added that there was another identified difficulty which was that the materials provided were different from the materials tested in the final exam and he had to learn the materials from his mobile phone when the modules arrived late. From several UPBJJ-UT points visited such as those in Malang, Jember, and Pontianak some students found themselves have no face-to-face tutorials at all since they lived apart one another and were busy with their teaching and households.

\subsection{Instructional Goals Identification}

It was quite surprising when the authors of the Atomic Physics PEFI 4421 Module who are from State University of Surabaya and State University of Malang acknowledged that they themselves have not seen the module that they wrote. It was the first time ever they got to see the module when being shown the module by the researcher. After the module titles arrangement being rearranged, and analysed, it was found that there were some overlapping contents 
distributed in different module titles, and some explanations were repeated in other modules. In the old modules, there were initially only 4 points described in the learning outcomes in regard to the ICT. This was later changed into 5 points of learning outcomes that are in compliance with KKNI and the explanations have now been more clearly and there are directions to use virtual laboratory and media.

In the old module, after the discussion of atomic model it was followed by a section for Schrodinger equation with three ICT formulations. In the new generation module of Atomic Physics further discussions on atomic models from Dalto, Thomson, Rutherford and Bohr are added. Also, in the previous module 2 there was still a discussion on electron spin while on the new module it was replaced by identifications of the properties of cathode rays with various kinds of pressure, magnetic fields, electric fields, and demonstrations of Milikan experiment using the virtual lab as well as formulation of the value of $\mathrm{e} / \mathrm{m}$. in Module 3 of the new generation there is a discussion on particles inside a dimension box using Schrodinger equation as well as implementation of the wave particle concept in relation to time and apply it to determine the value of particle expectation and it practical application in determining the energy level of hydrogen atom in the Bohr theory. As for Module 4, there was a discussion section put in the old module on the Zeeman effect while in the new generation module descriptions about kinds of quantum numbers, calculations on orbital and radial kinetic energy quantum, and explanations about the concept of Eigen function and the interpretations in angular and orbital momentum illustrations.

In the previous Module 5 of Atomic Physics, there was a discussion section on Multi-electron Atoms, instead in the new generation module there is a discussion section on Zeeman Effect. The five discussion points on multi-electron atoms are now put on the ICT section as there are only 4 learning outcomes to describe. In the previous Module 6 of the old module, there was a discussion on the spectrum of oxygen why in the new Module 6 it is replaced by a discussion on the spectrum of hydrogen. In that Module there were about 7 learning outcomes to achieve while there are now only 3 learning outcomes needed. In the old Module 7, in the section of orbital wave there were 6 points of ICT formulations, but in the new module regarding the discussion on multi-electron atoms they were limited to 2 learning outcomes. Next, in the previous Module 8, there were discussions on the spectrum of rotation and vibration which are formulated on 6 ICT points meanwhile in the new module the discussion on X-ray with 5 points of learning outcomes described. In the last learning outcome described, the students are expected to analyse the result of X-ray diffractions. Lastly, in the previous Module 9 of Atomic Physics there was a discussion on the electronic transmissions and basic concepts of laser The number of ICT description points of the new generation module there is only one single learning outcome to describe.

\subsection{Instructional Analysis Completion}

Changes in the discussion topics and module titles in Atomic Physics PEFI course modules were due to the advanced developments of science and technology. This was also because of the decision made by the authors of the modules when they sat together and select the currently relevant topics of discussions to include. This was also applied to the formulations of the learning outcomes of every topic discussion in every module with the same reason. During the discussions between the authors, there were argumentations occurred in regard to the proposals of topics included in the module, but this could be resolved by looking at the available resource books. The authors o the modules were 4 people from 2 different universities: 2 authors were from State University of Surabaya, while the other 2 were from State University of Malang.

\subsection{Learners and Contexts Analysis}

The students who can take the course on Atomic Physics PEFI4421 were those who already passed the Basic Physics course. The identified students' characteristics include: (1) being competent in Physics science at the undergraduate level which later will be passed on to the students in junior and senior high schools as well as vocational schools; (2) being competent in concept and strategy learning mastery of Physics for junior, senior and vocational school students which is oriented towards independent learning as a teacher and citizen that is good, intelligent, participatory, and responsible; (3) being able to organise the learning of Physics in an interesting and challenging way which in turn promotes the students to be independent and active in their own learning; (4) being able to practice their problem solving methods and related them in logical, systematic, consistent, and creative ways to the students; (5) being able to utilise a variety of tools, materials, media, and cutting edge learning technologies and actualise himself with a figure of an innovative and creative teacher; (6) being able to act and behave himself in his work environment and the society in accordance to his skills; (7) being able to provide examples to the students manifested in behaviours that are complied with the religion, The Five Principles, and the national regulations as well as to have well-spoken wordings and grammatical structures based on the national level of Indonesian language; (8) being able to improve learning quality through self- as well as peer-assessment; (9) being competent in other disciplines of knowledge 
(such as science) that are relevant for knowledge development as a teacher; (10) being able to apply implement the concepts of Physics in daily life contextually; (11) Being able to utilise any available learning resources in a way that the students have a better level of understanding, skills and emotion; (12) being competent in implementing various learning strategies in learning Physics; (13) being able to influence a good attitude, way of thinking, and scientific practice to the students; (14) being able to develop himself independently so as to follow the development of science and technology, politics, economy, social, culture, and security and defence; (15) being able to participate in professional organisations.

The educational background of the undergraduate students of Physics Education that took the course of Atomic Physics PEFI4421 are graduates from senior high school level, Diploma 1 of Physics/Science Education, Diploma 2 of Physics/Science Education, and Diploma 3/Bachelor of Science Equivalent Education, Pure Science Education and Physics Education level. The students had to fulfil the obligations as stated in the curriculum, access learning resources and support, and Virtual Reading Room (Ruang Baca Virtual/RBV), dry lab, supplement website addresses, online as well as face-to-face tutorials. From several interviews, it was found that some students were still not accustomed to having this independent learning style. Some students said that they felt alone since there was no friend available to discuss about the lesson and as the time went by one person even decided to transfer to the Biology major (Yudi Pokjar, Sambas-Pontianak). The students are required to be independent, if looking for friends to discuss with there is an option for online tutorials, where they can discuss any related topics with their peers and the lecturer that may support a friendship between them. The students were not used to systematic-learning also. The routine activities were limited to reading, learning and writing notes of the concepts that are regarded as important as a preparation for the final term exams. There was no self-discipline for a good learning-time management identified.

\subsection{Performance Objectives Writing}

\subsubsection{Previous ICT Problem and Learning Outcomes Formulation}

The module that is about to be developed has already used multimedia learning facilities. The four learning outcomes stated in Module 1 have already been deducted into only ICT learning outcome which is describing models of atom such as those founded by Dalton, Thomson, Rutherford and Bohr. As for Module 2, the previous learning outcomes were three and have now been reduced into two points only, they are (1) describing the characteristics of cathode ray with various pressures, magnetic fields, and electric fields and also (2) demonstrating Milikan experiment using the virtual laboratory an formulating the value of e/m. Whereas in Module 3, the learning outcomes have also been converted from 2 into 3 points by adding the ability to complete particle matter analysis inside a dimensional box using Schrodinger equation. In Module 4, the learning outcomes were developed into 5 points by assigning ICT to $\mathrm{C} 3$ and $\mathrm{C} 4$ level and requiring the students to be able to describe orbital angular momentum with various sub layers and be knowledgeable of the concept of spinors. Meanwhile, in Module 5, the learning outcomes have been changed from 5 points to 4 points as the learning outcomes were summarized and shortened and have already utilized the intended implementations and analyses.

Nevertheless, for Module 6, the number of points on the learning outcomes remained the same using much simpler operational words to determine the students' competence. For Module 7, the number of learning outcomes was reduced from 6 to 5 points because there are several concepts that can be put into one more general point. For Module 8, the new number of learning outcomes was 7 and the student was then required to be able to conduct analysis on the result of X-ray diffractions. In Module 9, the number of learning outcomes was converted from 4 to 5 points; this is because some concepts have vastly developed and at this point the students are required to be able to write a paper that is related to the recent application of laser technology in different fields.

\subsection{Assessment Instrument Development}

In developing the instruments for assessment the authors and researcher firstly discussed together to determine the points used for constructing the instruments. For the module materials of which assessment instruments are in the form of objective questions it is concluded that for every learning activity 10 questions will be made. The questions were constructed to require the students to be able to take the benefits from the available learning resources and ICT to look for information about the theory development proposed by Dalton, Thomson, Rutherford, and Bohr.

For the assessment instruments that require explanations to answer, some essay questions were then constructed accordingly. For instance, for Module 1 about Models of Atoms the question requires the students to describe the characteristics of the models of atom proposed by Dalton, Thomson, Rutherford, and Bohr. Furthermore, for Module 2 about Cathode-ray and Milikan experiment, the assessment instruments are in the form of objective questions referred from the stated learning outcomes such as asking the students to identify the characteristics of cathode ray 
with various types of pressures, magnetic fields, and electric fields. As for the essay questions, the students may then be asked to demonstrate MIlikan experiment using virtual laboratory and formulate the value of e/m since there was also a possibility to have an assessment instrument in the form of practicum. For Module 3, about Schrodinger Equation, the assessment instrument would be in the form of an objective test and essay to identify the achievement of the students' learning outcomes. The possibilities are (1) conducting analysis on the particle matter in a dimensional box using Schrodinger equation, (2) applying the concept of particle waves towards time and apply it in attempt to determine the expected value of the particle, (3) applying the knowledge of determining the energy level of hydrogen atom in Bohr's theory. As for Module 4 regarding Atom in the viewpoint of Quantum Theory, the instruments would be in the form of an objective test and essay. The students may be asked to (1) describe describe types of quantum numbers, (2) calculate particle energy, including kinetic (orbital and radial) and potential energy, (3) explain the concept of Eigen function and interpret it in the form of pictures or projections of angular orbital momentum with various sublayers, or (4) explain the concept of Spinor and identify the internal characteristics of particle (mass or charge).

Also, for Module 6 that discusses Hydrogen Spectrum, the instruments used for assessing the competences would also possibly be in the form of objective test and essay. The questions might then ask the students to (1) discuss the spectrum of hydrogen atom, (2) calculate the wavelength of each series of hydrogen spectrum, and (3) explain the spectrum of emission and absorption. $\mathrm{F}$ for Module 7 about Multi-electron Atom, the instruments of assessment would also be in the form of objective test and essay. For example, the questions may ask the students to (1) explain the concept of Pauli Exclusion Principle, electron configuration, and periodic table, and Hund's Rule, (2) explain the relation between Pauli Exclusion Principle the positions of electrons in a single atom. Next, for Module 8 of which topic is about X-ray, the instruments would also possibly be an objective test and essay in order to identify the following points of learning outcomes which are the ability to (1) identify the characteristics of X-ray, (2) differentiate between the characteristics of X-ray and Bremstrahlung radiation, (3) apply the Bragg's Law to solve problems, (4) explain the relationship between Moseley Plot and X-ray diffraction analysis results. Lastly, for Modul 9 about Laser, the possible instruments used for assessment would be in the form of objective test and essay to identify the learning outcomes of the students by asking the students to explain the basic process of laser and types of laser, as well as the implementation in various fields.

\subsection{Instructional Strategy Development}

Instructional strategy development was completed together between the module authors and researcher. With some serious discussions to determine the strategies that can possibly be applied for each learning outcome. Every learning outcome still uses a learning strategy in text form with some topics of discussion in Module 1 have been equipped with supplementary materials to describe the characteristics of atom model proposed by Dalton, Thomson, Rutherford and Bohr. Meanwhile the learning strategy set for Module 2 is for the students' benefits to be able to identify the characteristics of cathode ray with various pressures, magnetic fields and electric fields, demonstrate Milikan experiment using virtual laboratory as well as formulate the value of e/m. For Module 3, there was only one outcome with a supplementary material which was analysing particles inside a dimensional box using Schrodinger equation. Meanwhile for both Module 4 and 5 all the learning outcomes were equipped with supplementary materials. For Module 6, of which specific instructional purpose is to explain the spectrum of hydrogen atom, calculate the wavelength of each series of hydrogen spectrum and explain the spectrum between emission and absorption, be skilful in developing the materials for spectrum in the form of presentation and its implementation in life. Next, for Module 7, the supplementary material was used for explaining the concept of Pauli Exclusion Principle for the placement of electrons in an atom. In Module 8, the supplementary strategy was not used. Then, in Module 9, the supplementary strategy was used to explain the basic process of laser, types of laser and the implications in various disciplines.

\section{Conclusion}

Based on the findings and discussions, it is concluded from this research study that:

1. The instructional materials of Atomic Physics are in need of improvement and revision since it has been used for a long time containing some outdated materials.

2. The materials and concepts covered in atomic Physics are still hard to understand by the students independently without an option for face-to-face tutorials.

3. The sample questions on each module have not been explained in details promoting difficulties to the students 
4. The package/physical presentation of the module textbooks for Atomic Physics need some improvement because it failed to attract the students' learning interest.

\section{References}

Borg \& Gall (1983). Educational Research, An Introduction. New York and London. Longman Inc.

Dick, W, Carey L., \& Carey, J.O. (2009). The Sitematic Design of Instruction Columbus: Ohio, Person.

Djamarah, Syaiful Bahri. (2000). Strategi Belajar Mengajar. Jakarta: Penerbit Rineka Cipta.

Djemari, Mardapi. (2008). Tekhnik penyusunan instrumen tes dan nontes. Yogyakarta: Mitra Cendikia Press.

Hamzah B. Uno. (2007). Teori Motivasi dan Pengukurannya Analisis di Bidang Pendidikan, Bumi Aksara, Jakarta.

Jonassen, D.H. (1991).Objectivism versus constructivism:do we need a new philosophical paradigm? Education alTechnology Research and Development, 39(3), 5-14. https://doi.org/10.1007/BF02296434

Oemar Hamalik. (2005). Kurikulum dan Pembelajaran. Jakarta: Bumi Aksara.

Permendiknas RI No. 52 Tahun 2008 tentang Standar Proses.

Plomp, Tj. (1994). Educational Design: Introduction. From Tjeerd Plomp (eds). Educational \&Training System Design: Introduction. Design of Education and Training (in Dutch). Utrecht (the Netherlands): Lemma. Netherland. Faculty of Educational Science andTechnology, University of Twentee.

Seels, Barbara B., \& Richey, Rita C. (1994). Teknologi Pembelajaran: Definisi dan Kawasannya. Penerjemah Dewi S. Prawiradilaga dkk. Jakarta: Kerjasama IPTPI LPTK UNJ.

Suparman, M.A. (2014). Teknologi Pendidikan dalam pendidikan Jarak Jauh: Solusi Untuk Kualitas dan Aksesibilitas Pendidikan. Tangerang Selatan: Universita Terbuka. 